\title{
ATIVIDADE DA ENZIMA REDUTASE DO NITRATO EM ALGODOEIRO SUBMETIDO AO DÉFICIT HÍDRICO E POSTERIOR RECUPERAÇÃO DA TURGESCÊNCIA
}

\author{
Celso Jamil Marur ${ }^{1 *}$; Paulo Mazzafera²; Antonio Celso Magalhães² \\ ${ }^{1}$ Área de Ecofisiologia - IAPAR, C.P. 481 - CEP: 86001-970 - Londrina, PR. \\ ${ }^{2}$ Depto. de Fisiologia Vegetal - Instituto de Biologia/UNICAMP, C.P. 6109 - CEP: 13083-970 - Campinas, SP. \\ *Autor correspondente <cjmarur@pr.gov.br>
}

RESUMO: A atividade da redutase do nitrato foi estudada em plantas de algodão (Gossypium hirsutum, L.), cvs IAC 20 e IAC 13-1, submetidas a déficits crescentes de água, e posterior recuperação da turgescência. A atividade fisiológica das folhas, representada pela atividade da enzima, sofreu redução quando $0 \psi_{\mathrm{a}}$ foi menor que -1,5 MPa. Não ocorreram diferenças significativas entre os dois cultivares em relação ao estabelecimento do estresse, nem tampouco quanto ao padrão de recuperação da turgescência em plantas estressadas. $O$ ensaio in vivo da atividade da redutase do nitrato mostrou ser um método sensível para a avaliação do efeito do estresse hídrico sobre o crescimento das plantas, constituindo-se em um parâmetro indicativo do nível geral do metabolismo na planta.

Palavras-chave: Gossypium hirsutum, potencial total da água

\section{NITRATE REDUCTASE ACTIVITY IN COTTON PLANTS UNDER WATER DEFICIT AND AFTER TURGESCENCE RECOVERY}

\begin{abstract}
The activity of the enzyme nitrate reductase was studied in cotton plants (Gossypium hirsutum, L), cvs IAC 20 e IAC 13-1, subjected to increasing water deficits, and after turgescence recovery. The physiological activity of the leaves, represented by the activity of the enzyme, was decreased for water potentials bellow -1.5 $\mathrm{MPa}$. Cultivars were not statistically different. Nitrate reductase activity was a very sensitive method to evaluate the effects of water stress on plant growth, being an indicative of plant metabolism.

Key words: Gossypium hirsutum, total water potential
\end{abstract}

\section{INTRODUÇÃO}

Uma resposta fisiológica particularmente sensível à redução do potencial da água $\left(\psi_{\mathrm{a}}\right)$ em plantas é a alteração da síntese protéica, associada à estruturação dos polissomas e aos processos de transcrição e tradução (Morilla et al., 1973). Como consequência, algumas enzimas que apresentam alta relação síntese:degradação, como a redutase do nitrato (RN) (Meyers Júnior et al., 1986), exibem forte inibição à redução do $\psi_{\mathrm{a}}$. A RN é a primeira enzima na via de assimilação do nitrato, e provávelmente representa o passo limitante na incorporação desse nutriente (Campbell, 1988). Em função de sua importância, ela tem sido frequentemente utilizada como indicadora de estresses e de outras mudanças associadas aos fatores moduladores do crescimento das plantas (Srivastava, 1980; Carelli et al., 1996). O déficit hídrico é responsável pela redução da atividade dessa enzima em cevada (Huffaker et al., 1970; Bandurska, 1991), milho (Morilla et al., 1973), sorgo (Teare et al., 1974), soja (Manam et al., 1977; Dong et al., 1995), trigo (Heuer et al., 1979), café (Meguro \& Magalhães, 1983), feijão (Castrillo et al., 1990) e tabaco (Wang et al., 1996).

A capacidade de uma planta recuperar-se de estresses de água temporários e/ou prolongados, e também a identificação da taxa desta recuperação, são de grande importância para a produção vegetal, pois estão ligadas à eficiência do uso da água pelas plantas e, consequentemente, à produtividade agrícola. Em plantas de cevada estressadas, verificou-se que a atividade da redutase do nitrato (ARN) recuperava-se completamente 24 h após a irrigação (Huffaker et al.,1970). Em plântulas estressadas de milho, houve completa recuperação do $\psi_{\mathrm{a}} 6 \mathrm{~h}$ após a irrigação com solução nutritiva livre de nitrato (Morilla et al., 1973), sendo que no mesmo período, a ARN também alcançou o nível de $76 \%$ em relação ao controle.

Embora o algodoeiro apresente um alto grau de tolerância ao déficit hídrico em certos estádios do seu desenvolvimento (Doorenbos \& Kassam, 1979), em alguns anos a produção de algodão é afetada devido a esta adversidade climática. Ackerson et al. (1977) verificaram que a ARN foi adversamente afetada em plantas de algodão submetidas ao estresse hídrico. Observaram que, ao meio-dia, quando o $\psi_{\mathrm{a}}$ na folha atingiu um valor $0,9 \mathrm{MPa}$ menor que nas plantas controle, a $\mathrm{RN}$ teve a sua atividade reduzida para aproximadamente $30 \%$ dos valores observados no tratamento controle.

O efeito das temperaturas do ar e da folha sobre a ARN também pode ser avaliado utilizando-se a metodologia das curvas de Arrhenius, que indicam mudanças abruptas na energia de ativação que surgem 
devido a alterações na conformação da enzima ou na natureza dos processos cinéticos (Silvius et al., 1978).

No Brasil, o cultivar IAC 20 foi o algodoeiro mais cultivado nos últimos anos, e é ainda utilizado no melhoramento genético para obtenção de novos materiais. Em experimentos de comparação de materiais conduzidos na década de 60, a variedade IAC 13-1 apresentou uma certa tolerância à seca, possivelmente em função de que a sua seleção foi realizada sob sêca (Inforzato \& Fuzatto, 1967). No entanto, a magnitude dos efeitos da seca sobre alguns parâmetros fisiológicos de plantas de algodão cultivados na região sul do Brasil é pouco conhecida. Assim, o objetivo deste trabalho foi avaliar as alterações da atividade da enzima redutase do nitrato em resposta ao estabelecimento de um estresse hídrico crescente, e também à recuperação da turgescência de plantas estressadas dos cultivares de algodoeiro IAC 13-1 e IAC 20.

\section{MATERIAL E MÉTODOS}

Plantas de algodão (Gossypium hirsutum L.) dos cultivares IAC 13-1 e IAC 20 foram utilizadas para avaliação do comportamento da enzima RN.

\section{Experimento 1 - Estabelecimento do déficit hídrico}

As plantas foram cultivadas em casa de vegetação, em 30 vasos de $5 \mathrm{~L}$ para cada cultivar, contendo substrato formado por terra, areia e torta de mamona (35:45:20), e um adequado suprimento de adubo mineral, composto por salitre do Chile, super-fosfato triplo e cloreto de potássio, recomendado por Malavolta et al. (1974). Foram semeadas de seis a oito sementes por vaso, e aos dez dias após a emergência permaneceram três plântulas por vaso. Aos vinte dias procedeu-se à raleação final, mantendo-se a planta mais vigorosa no vaso. As plantas foram submetidas aos tratamentos fitossanitários normalmente preconizados para a cultura.

A partir da emergência, a cada dois dias as plantas foram supridas com água e a cada duas semanas com $0.5 \mathrm{~L}$ de solução de Hoagland $1 / 2$ concentração. No início do florescimento procedeu-se à última irrigação normal. A partir daí, a cada dia fez-se a reposição de cêrca de $50 \%$ da água perdida por evapotranspiração, estimada pela pesagem dos vasos, a fim de estender o período de estabelecimento de deficiência hídrica (Marur, 1999).

Diariamente, à medida que as plantas experimentavam menor disponibilidade de água, três plantas de cada cultivar foram levadas para uma câmara de crescimento com ambiente controlado (Conviron), com o fluxo de radiação fotossintéticamente ativa na altura do ápice das plantas de $550 \mu \mathrm{mol} \mathrm{m}^{-2} \mathrm{~s}^{-1}$, temperatura do ar no interior da câmara de $26^{\circ} \mathrm{C} \pm 2^{\circ} \mathrm{C}$ e umidade relativa do ar aproximadamente $65 \%$. Duas horas e trinta minutos após a transferência das plantas para a câmara climatizada, os dois cultivares foram seguida e alternadamente avaliados.
Em cada planta, medições das temperaturas do ar e da última folha verdadeira totalmente expandida, em cada planta, foram realizadas com o termopar de uma câmara portátil de fotossíntese LI-COR, modelo LI-6200. Em seguida, a folha teve o pecíolo seccionado com bisturi, e imediatamente acondicionada em uma câmara de pressão (PMS Instruments) para a avaliação do $\psi_{\text {a }}$. Da mesma folha foram então coletados 6 discos com $11 \mathrm{~mm}$ de diâmetro, que foram cortados em tiras de $1 \mathrm{~mm}$ de largura, por meio de um conjunto de lâminas paralelas. $O$ material foi transferido para frasco contendo $10 \mathrm{ml}$ de 0,1 $\mathrm{M}$ tampão fosfato, $\mathrm{pH} 7,5,0,03 \mathrm{M} \mathrm{KNO}_{3}$ e 1\% 1-propanol, infiltrado a vácuo por dois períodos de 5 minutos cada, e incubado no escuro, por 60 minutos, em banho-maria a $30^{\circ} \mathrm{C}$, com agitação constante (Radin, 1974). Após a incubação, alíquotas foram retiradas e nelas dosadas 0 nitrito formado. Os discos foram recuperados do meio de incubação e secos em estufa para a determinação da matéria seca. A atividade da enzima foi expressa em mmoles de $\mathrm{NO}_{2} \mathrm{~kg}^{-1} \mathrm{MS} \mathrm{h}^{-1}$. Os pontos foram definidos numa relação $X^{2}: Y$ e ajustados por meio de uma função cúbica (Zullo Júnior. \& Arruda, 1986). Para a confecção das curvas de Arrhenius, o logaritmo neperiano da ARN foi plotado em função do inverso dos parâmetros temperaturas do ar e da folha, em ${ }^{\circ} \mathrm{K}$. (Silvius et al., 1978). A comparação das linhas de regressão dos cultivares foi feita pelo método desenvolvido por Neter \& Wasserman (1974).

$O$ restante da folha usada para determinação do $\psi_{\mathrm{a}}$ e da atividade da RN foi acondicionado em frasco de vidro e mantido sob gêlo. Ao final da coleta diária, esse material foi congelado e liofilizado. Posteriormente, as amostras foram maceradas e levadas para extração em metanol:clorofórmio:água (12:5:3, v/v/v), como descrito por Bielesky \& Turner (1966). Após remoção da clorofila por separação de fase, um volume da fase aquosa foi evaporada, solubilizada em água destilada e utilizada para determinação de nitrato (Cataldo et al., 1975).

\section{Experimento 2 - Recuperação da turgescência}

Plantas dos dois cultivares foram cultivadas em casa de vegetação, em vasos de $1 \mathrm{~L}$ contendo areia lavada, e irrigadas periodicamente com água destilada. Quando as plantas encontravam-se no estádio de cinco folhas (próximo ao início da formação do primeiro botão floral), a irrigação foi interrompida para o estabelecimento do estresse hídrico. O acompanhamento do desenvolvimento do estresse hídrico foi feito diariamente através da medição com a câmara de pressão. Quando o $\psi_{\text {a }}$ de algumas plantas amostradas se aproximou de -2,2 $\mathrm{MPa}$, as plantas foram transferidas para câmara de crescimento com as mesmas condições citadas anteriormente. Duas horas e trinta minutos após a transferência, as folhas de 3 plantas de cada cultivar foram coletadas para a estimativa da atividade enzimática. De cada folha foram coletados 2 discos com $11 \mathrm{~mm}$ de diâmetro e procedeu-se, então, à mesma sequência 
descrita anteriormente para a análise da ARN. Em seguida, um lote de plantas, de cada cultivar, foi irrigado com água destilada e um outro com uma solução $50 \mathrm{mM}$ de salitre do Chile, e a ARN avaliada aos 30, 60, 120 e 240 minutos após a irrigação. Em cada período de avaliação os dados foram submetidos a analise de variância, e o teste Tukey foi aplicado para a comparação das médias, utilizando-se 95\% de nível de confiança.

Entre as plantas irrigadas somente com água destilada, procedeu-se também à avaliação do $\psi_{\mathrm{a}}$ durante o processo de recuperação da turgescência. $O \psi_{a}$ foi avaliado em intervalos de 5 minutos, alternadamente em cada cultivar. Os valores de $\psi_{\mathrm{a}}$ em relação ao tempo foram definidos numa relação $X: Y$ e ajustados por meio de uma função polinomial assimétrica (Pereira \& Arruda, 1987). A comparação das linhas de regressão dos cultivares foi feita de acordo com Neter \& Wasserman (1974).

\section{RESULTADOS}

\section{Experimento 1 - Estabelecimento do déficit hídrico}

A reposição diária de cêrca de $50 \%$ da água perdida por evapotranspiração estendeu o período de estabelecimento da deficiência hídrica por dez dias.

O teste de comparação das curvas indicou não haver diferença significativa entre os dois cultivares, daí a apresentação de uma única linha de regressão para ambos os cultivares. Nota-se uma relação exponencial entre os valores de ARN e $\psi_{a}$ na folha compreendidos entre -0,7 e -1,4 MPa e que valores de $\psi_{\mathrm{a}}$ abaixo de -1.5 MPa causaram inibição quase total da ARN (Figura 1).

Os níveis de nitrato nas folhas se mantiveram entre 2 a $3 \mathrm{~g} \mathrm{~kg}^{-1} \mathrm{MS}$, o que indica um bom suprimento desse nutriente (Ackerson et al., 1977).

As relações existentes entre a $A R N$ e as temperaturas da folha e do ar são mostradas como curvas de Arrhenius (Figura 2). Com relação à temperatura da folha (Figura 2-A), a alteração do padrão de atividade enzimática ocorreu aproximadamente à $25^{\circ} \mathrm{C}$ (valor obtido

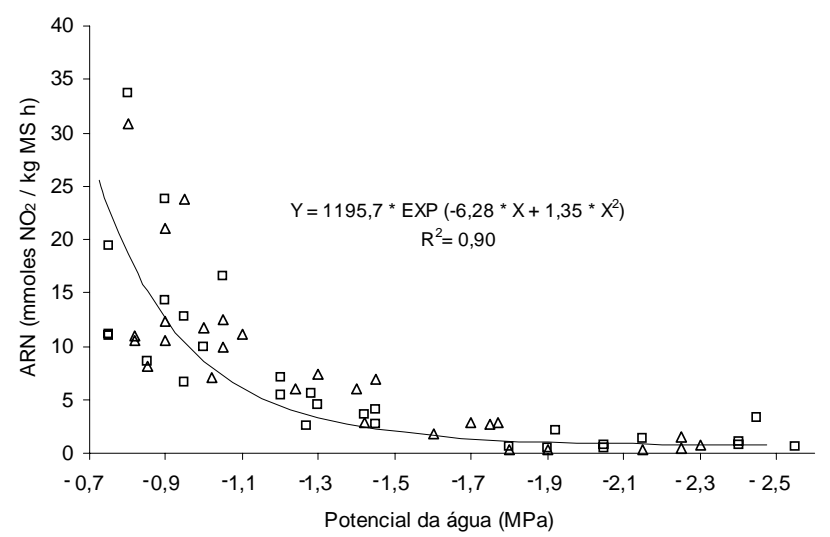

Figura 1 - Atividade da enzima redutase do nitrato (ARN) em diferentes potenciais da água na folha $\left(\psi_{\mathrm{a}}\right)$, para os cultivares IAC 13-1 $(\square)$ e IAC $20(\Delta)$. A linha refere-se ao ajustamento de uma função cúbica, para ambas cultivares. através das devidas transformações aritméticas). Com respeito à diferença entre as temperaturas da folha e do ar observou-se, também, que a mudança na inclinação da curva de atividade enzimática deu-se quando aquela foi de aproximadamente $0,1^{\circ} \mathrm{C}$ (Figura $2-\mathrm{B}$ ).
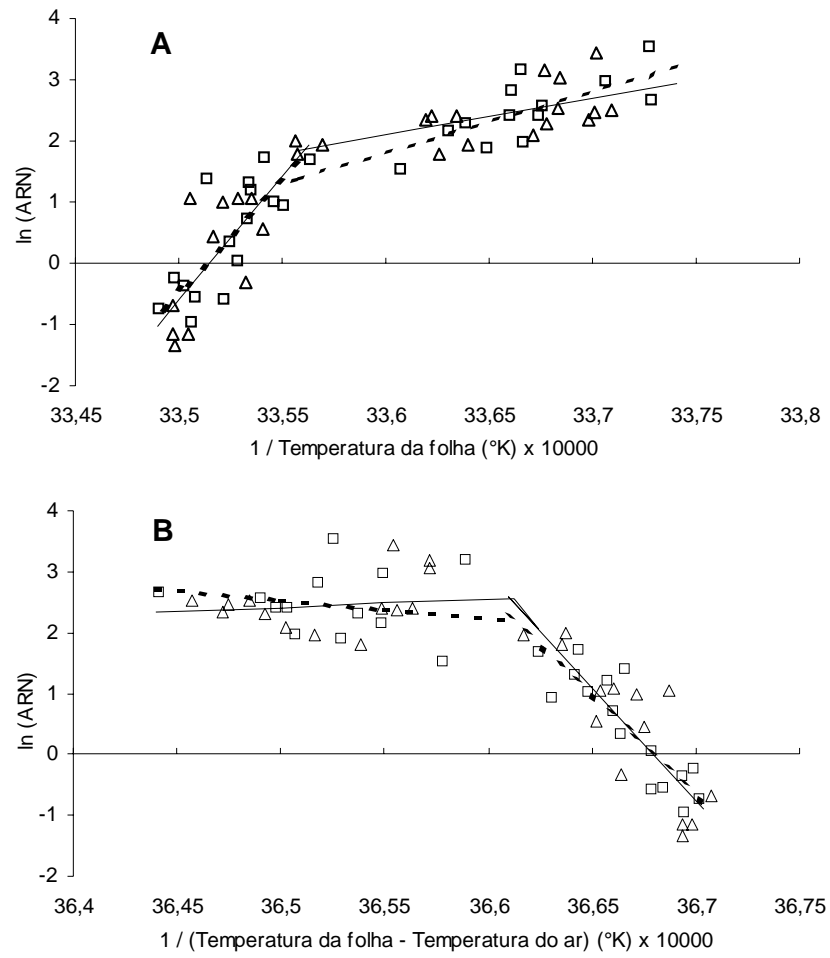

Figura 2 - Atividade da redutase do nitrato (ARN) em diferentes temperaturas da folha dos cultivares IAC 13-1 ( $\square$ ) e IAC $20(\Delta)$ (Figura 2-A), e em função das diferenças entre as temperaturas do ar e da folha (Figura 2-B). As linhas referem-se ao ajustamento de funções lineares (IAC 13-1, linha tracejada; IAC 20, linha cheia)

\section{Experimento 2 - Recuperação da turgescência}

Em plantas estressadas e irrigadas somente com água, a ARN permaneceu práticamente estável e bastante inferior àquela obtida para as plantas supridas com nitrogênio (Figura 3). Nas plantas supridas com nitrato a enzima apresentou um aumento constante de atividade durante os primeiros 120 minutos de reidratação, quando atingiu os valores máximos. Observa-se que a ARN no cultivar IAC 20 foi ligeiramente superior que no IAC 13-1.

Os valores de $\psi_{\mathrm{a}}$ obtidos durante o período de recuperação da turgescência são mostrados na Figura 4. Nos 30 minutos iniciais as plantas recuperaram cerca da metade da energia potencial da água atingida ao final do período de avaliação, com $0 \psi_{\mathrm{a}}$ nas folhas aumentando de $-2,1$ para $-1,3 \mathrm{MPa}$. Entre os 30 e 90 minutos a recuperação foi mais lenta, com alterações de $-1,3$ a $-0,85$ $\mathrm{MPa}$. Somente aos 150 minutos ocorreu a recuperação total do potencial da água na folha, atingindo valores próximos a -0,6 MPa. O teste de comparação das curvas indicou não haver diferença entre os cultivares, daí a apresentação de uma só linha de regressão. 


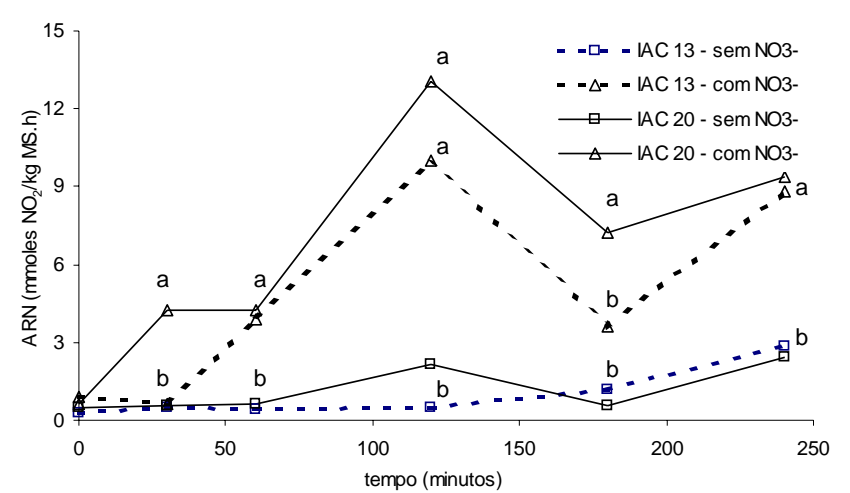

Figura 3 - Atividade da redutase do nitrato (ARN) durante o período de recuperação da turgescência, para os cultivares IAC 13-1 e IAC 20, em plantas deficientes ou supridas com $\mathrm{NO}_{3}$.

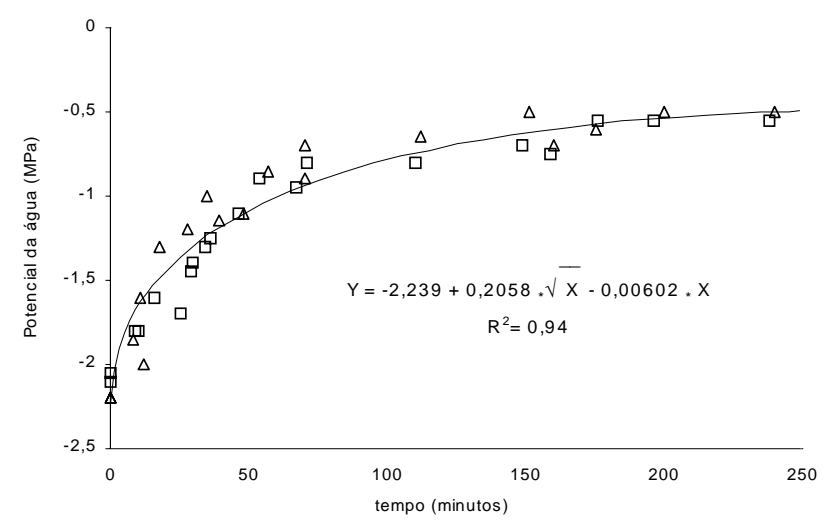

Figura 4 - Potencial da água nas folhas $\left(\psi_{\mathrm{a}}\right)$ durante o período de recuperação da turgescência, para os cultivares IAC 13$1(\square)$ e IAC $20(\Delta)$. A linha refere-se ao ajustamento de uma função polinomial assimétrica, para ambos cultivares.

\section{DISCUSSÃO}

A sensibilidade da ARN foi observada durante 0 estabelecimento do déficit hídrico, com significativa inibição entre $\psi_{\mathrm{a}}$ na folha entre $-0,7$ e $-1,4 \mathrm{MPa}$ (Figura 1), comportamento muito semelhante ao observado por Manam et al. (1977) em folhas de soja. Em sorgo, a ARN também foi substancialmente reduzida quando $0 \psi_{\mathrm{a}}$ na folha aproximou-se de -1,5 MPa (Teare et al., 1974), e a inibição da atividade foi observada em cevada quando o $\psi_{\mathrm{a}}$ atingiu -1,2 MPa (Huffaker et al., 1970). Meguro \& Magalhães (1983), utilizando diferentes cultivares de cafeeiro, observaram uma significativa redução da atividade da enzima em valores de $\psi_{\mathrm{a}}$ entre $-1,0$ e $-3,0$ $\mathrm{MPa}$ e em milho foi observada uma redução de $98 \%$ na $\mathrm{ARN}$, quando o potencial da água alcançou $-1,2 \mathrm{MPa}$ (Becker e Fock, 1986).

$\mathrm{O} \psi_{\mathrm{a}}$ na folha de $-1,5 \mathrm{MPa}$, abaixo do qual ocorreu paralisação quase total da ARN no presente trabalho, foi similar ao observado por Marur (1999), onde foi verificada paralisação da expansão foliar nos mesmos cultivares.

Pelo conceito do balanço de energia, sabe-se que à medida que o componente "calor latente de vaporização" é diminuído, pode ocorrer um aumento do componente "calor sensível". Sabe-se, também, que temperaturas da folha maiores que temperaturas do ar indicam restrição na disponibilidade de água para a planta. Assim, a partir do momento em que não existe mais diferença entre as temperaturas do ar e da folha, a tendência é o aumento desta última, em função do armazenamento de parte da energia que incide no tecido foliar, e que não é mais dissipada por transpiração. A Figura 2-B evidencia este fato e mostra, alternativamente à medição do potencial da água na folha, que as diferenças entre as temperaturas da folha e do ar também podem ser usadas para indicar o efeito do estresse hídrico sobre a ARN.

Como os teores de nitrato nas folhas de algodão, durante 0 experimento de estabelecimento do déficit

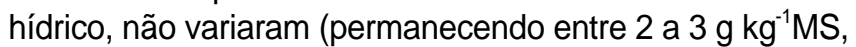
mostrando haver bom suprimento desse nutriente), a queda na ARN parece ter ocorrido exclusivamente devido aos valores decrescentes de $\psi_{\mathrm{a}}$ na folha, que limitariam 0 transporte do nitrato.

No processo de recuperação da turgescência, os dois cultivares não mostraram diferenças significativas durante a retomada do $\psi_{\mathrm{a}}$. Com relação à enzima, sua atividade permaneceu inalterada e em nível baixo nas plantas deficientes de nitrato, enquanto que nas plantas supridas com este nutriente foi apresentada uma taxa de aumento constante durante os primeiros 120 minutos (Figura 3). Entretanto, os valores máximos da ARN obtidos pelas plantas supridas com $\mathrm{NO}_{3}$ estiveram bem abaixo daqueles obtidos em plantas em estado normal de turgescência e bem supridas com $\mathrm{NO}_{3}$ (Figura 1). Experimentos com milho indicaram que a recuperação da ARN ocorreu aproximadamente $4 \mathrm{~h}$ após as folhas terem sido supridas com água e nitrato (Shaner e Boyer, 1976), e atingiram níveis de aproximadamente $50 \%$ da atividade da planta controle. Também em milho, a irrigação de plântulas estressadas com solução nutritiva livre de nitrato resultou em completa recuperação do $\psi_{\mathrm{a}}$ após $6 \mathrm{~h}$ (Morilla et al., 1973) e, ao final deste período, a ARN foi de $76 \%$ em relação ao controle. Durante este período não houve alterações nos conteúdos de nitrato no tecido foliar, o que levou os autores sugerirem que os níveis de nitrato nas folhas estressadas foram suficientes para promover altas ARN. Em cevada, Huffaker et al. (1970) verificaram que sómente 24 horas após a irrigação de plantas estressadas houve recuperação da ARN.

Segundo Sinha \& Nicholas (1981), é possível que a inibição da ARN se constitua em um processo regulatório na ausência de crescimento ativo em plantas estressadas, que evoluiu no sentido de conservar energia quando a fotossíntese é diminuída. Assim, como a conservação de energia é um requisito essencial para a sobrevivência durante o estresse, supõe-se que uma rápida redução da ARN se traduza numa vantagem metabólica. No entanto, seria importante que um cultivar apresentasse alta ARN logo após a recuperação do estresse, para que a retomada da síntese protéica ocorra rapidamente. 


\section{REFERÊNCIAS BIBLIOGRÁFICAS}

ACKERSON, R.C.; KRIEG, D.R.; HARING, C.L.; CHANG, N. Effects of plant water status on stomatal activity, photosynthesis and nitrate reductase activity of field grown cotton. Crop Science, v.17, p.81-84, 1977.

BANDURSKA, H. Effect of proline on nitrate reductase activity in water-stressed barley leaves. Acta Physiologiae Plantarum, v.13, p.3-11, 1991.

BECKER, T.W.; FOCK, H.P. Effects of water stress on the gas exchange, the activities of some enzymes of carbon and nitrogen metabolism, and on the pool sizes of some organic acids in maize leaves. Photosynthesis Research, v.8, p.175-181, 1986.

BIELESKY, R.L.; TURNER, N.A. Separation and estimation of aminoacid in crude plant extracts by thin-layer electrophoresis and chromatography. Analytical Biochemestry, v.17, p.278-293, 1966.

CAMPBELL, W.H. Nitrate reductase and its role in nitrate assimilation in plants. Physiologia Plantarum, v.74, p.214-219, 1988.

CARELLI, M.L.C.; UNGARO, M.R.G.; FAHL, J.I.; NOVO, M.C.S.S. Níveis de nitrogênio, metabolismo, crescimento e produção de girassol. Revista Brasileira de Fisiologia Vegetal, v.8, p.123-130, 1996.

CASTRILLO, M.; FERNANDEZ; P. MOLINA, B.; KAZANDJIAN, A. Nitrogen metabolism in Phaseolus vulgaris $L$. under water deficit. Turrialba, v.40, p.515-519, 1990.

CATALDO D.A.; HAROON, M.; SCHRADEV, L.E.; YOUNGS, V.L. Rapid colorimetric determination of nitrate in plant tissue by nitration of salicylic acid. Communications in Soil Science and Plant Analysis, v.6, p.71-80, 1975.

DOORENBOS, J.; KASSAN, A.H. Yield response to water: irrigation and drainage. Roma: FAO, 1979. 193 p. (Paper, 33).

DONG, Z.A.; XIE, F.T. Effects of drought treatments at different stages on the enzyme activities and membrane permeabilities of soyabeans. Soybean Science, v.14, p.290-298, 1995.

HEUER, B.; PLAUT, N.; FEDERMAN, E. Nitrate and nitrite reduction in wheat leaves as affected by different types of water stress. Physiologia Plantarum, v.46, p.318-323, 1979.

HUFFAKER, R.C.; RADIN, T.; KLEINKOPF, G.E.; COX, E.L. Effects of mild water stress on enzymes of nitrate assimilation and of carboxylative phase of photosynthesis in barley. Crop Science, v.10, p.471-474, 1970.

INFORZATO, R.; FUZATTO, M.G. Estudo comparativo de transpiração em três variedades paulistas de algodoeiro. Bragantia, v.26, p.59-61, 1967.

MANAM, R.; TEARE, I.D.; POWERS, W.L.; SKIDMORE, E.L. Nitrate reductase activity of soybeans in relation to other indicators of water stress. Phyton, v.35, p.189-194, 1977.

MALAVOLTA, E.; HAAG, H.P.; MELLO, F.A.F.; BRASIL SOBRINHO, M.O.C. Nutrição mineral e adubação de plantas cultivadas. São Paulo: Pioneira, 1974. p.179-201: Nutrição mineral e adubação do algodoeiro.
MARUR, C.J. Curvas pressão-volume e expansão foliar em dois cultivares de algodoeiro submetidos a déficit hídrico. Scientia Agricola, v.56, p.563-569, 1999.

MEGURO, N.E.; MAGALHÃES, A.C. Water stress affecting nitrate reduction and leaf diffusive resistance in Coffea arabica L. cultivars. 1983. Journal of Horticultural Science, v.58, p.147-152, 1983.

MEYERS JUNIOR., O.; YOPP, J.H.; KRISHNAMANI, M.R.S. Plant breeding reviews. West Port: AVI, 1986. v.4, p.203-243: Breeding soybeans for drought resistance

MORILLA, C.; BOYER, J.S.; HAGEMAN, R.H. Nitrate reductase activity and polyribosomal content of corn having low leaf water potential. Plant Physiology, v.51, p.817-824, 1973.

NETER, J.; WASSERMAN, W. Applied linear statistical models: regression, analysis of variance and experimental designs. Homewood: Richard D. Irwin, 1974. p.140-213: Topics in regression analysis

PEREIRA, A.R.; ARRUDA, H.V. Ajuste prático de curvas na pesquisa biológica. Campinas: Fundação Cargill, 1987. 50p.

RADIN, J.W. Distribution and development of nitrate reductase activity in germinating cotton seedlings Plant Physiology, v.53, p.458-463, 1974

SHANER, D.L.; BOYER, J.S. Nitrate reductase activity in maize leaves: II. Regulation by nitrate flux at low leaf water potential. Plant Physiology, v.58, p.505-509, 1976.

SILVIUS, J.R.; READ, B.D.; McELHANEY, R.N. Membrane enzymes: artifacts in Arrhenius plots due to temperature dependence of substract-binding affinity. Science, v.199, p.902-904, 1978.

SINHA, S.K.; NICHOLAS, D.J.D. Nitrate Reductase. In: PALEG, L.G.; ASPINALL, D. (Ed.) The physiology and biochemistry of drought resistance in plants. New York: Academic Press. 1981. p.145-168.

SRIVASTAVA, H.S. Regulation of nitrate reductase activity in higher plants. Phytochemistry, v.19, p.725-731, 1980.

TEARE, I.D.; MANAM, R.; KANEMASU, E.T. Diurnal and seasonal trends in nitrate reductase activity in field grown plants. Agronomy Journal, v.66, p.733-736, 1974.

WANG, Y.F.; HAN, J.F.; LIN, X.W. Study on physiological and biochemical responses of flue-cured tobacco to drought stress during early growth of the plants. Acta Agronomica Sinica, v.22, p.117-121, 1996.

ZULLO JÚNIOR., J.; ARRUDA, F.B. Programa computacional para ajuste de equações em dados experimentais. Campinas: Instituto Agronômico, 1986. 23p. (Boletim Técnico, 113).

Recebido em 20.09.99 